\title{
PENGUJIAN VALIDITAS DAN RELIABILITAS KONSTRUK PADA ORGANIZATIONAL CITIZENSHIP BEHAVIOR
}

\author{
Fatwa Tentama ${ }^{1}$, Subardjo $^{2}$ \\ ${ }^{1}$ Fakultas Psikologi, Universitas Ahmad Dahlan Yogyakarta, \\ Jalan Kapas 9 Semaki, Umbulharjo, Yogyakarta 551662 \\ ${ }^{2}$ Fakultas Hukum, Universitas Ahmad Dahlan Yogyakarta, \\ Jalan Pramuka 42, Sidikan, Yogyakarta 55161 \\ 11 fatwa.tentama@psy.uad.ac.id
}

\begin{abstract}
The purpose of this study was to test the construct validity and reliability of OCB scale, to determine the contribution of these aspects and indicators to measure variables OCB and confirming the hypothesized models that match the model with data through Second order confirmatory factor analysis (2nd Order CFA). This study involved 202 employees in organization $\mathrm{X}$ as samples that were chosen through non-probability sampling with convenience sampling. Linear Structural Model (LISREL) version 8.71 of Joreskog and Sorbom was used to analyze the data. The result showed that the aspect of conscientiousness, altruism, civic virtue, sportsmanship, and courtesy is able to reflect the variable OCB positively, valid and significant, supported by behavioral indicators of each aspect. Theoretical model of OCB fit with empirical data. OCB aspects are valid, significant and reliable to measure OCB employees. The most dominant aspect that reflects OCB is altruism and the weakest aspect is sportmanship.
\end{abstract}

Keywords: confirmatory factor analysis, organizational citizenship behavior, structural equation modeling

\begin{abstract}
Abstrak
Penelitian ini bertujuan untuk menguji validitas dan reliabilitas konstruk skala OCB, mengetahui kontribusi aspek-aspek dan indikator-indikator OCB dalam mengukur variabel OCB serta mengkonfirmasikan model yang dihipotesiskan yaitu kecocokan model dengan data dengan menggunakan Second order confirmatory factor analysis ( $2^{\text {nd }}$ Order $C F A$ ). Populasi dalam penelitian ini adalah semua karyawan di organisasi $\mathrm{X}$ dengan jumlah sampel sebanyak 202 orang. Sampel diambil menggunakan teknik nonprobability sampling yang dilakukan dengan convenience sampling. Analisis data dilakukan dengan menggunakan Linear Structural Model (LISREL) versi 8.71 dari Joreskog dan Sorbom. Hasil analisis menunjukkan bahwa aspek conscientiousness, altruism, civic virtue, sportmanship, dan courtesy mampu merefleksikan variabel OCB secara positif, valid dan signifikan yang didukung dengan indikator-indikator perilaku masing-masing aspek. Model teoritik variabel OCB sesuai (fit) dengan data empirik. Aspek-aspek OCB valid dan signifikan serta reliabel untuk mengukur OCB karyawan. Aspek paling dominan yang merefleksikan OCB adalah aspek altruism dan aspek paling lemah adalah sportmanship.
\end{abstract}


Kata Kunci: confirmatory factor analysis, organizational citizenship behavior, structural equation modeling

\section{Pendahuluan}

Sumber daya manusia merupakan aset yang berharga dalam suatu organisasi yang menjadi perencana, pengatur, dan pelaku aktif dari setiap aktivitas organisasi serta penentu terwujudnya tujuan organisasi (Hasibuan, 2012). Rebbeca dan Niehoff (2002) mengemukakan bahwa untuk meningkatkan kualitas sumber daya manusia maka dapat diwujudkan dengan mengembangkan Organizational Citizenship Behavior (OCB) pada karyawan. OCB merupakan perilaku karyawan yang dilakukan dengan sukarela, tulus, senang hati tanpa harus diperintah dan dikendalikan oleh organisasi dalam memberikan pelayanan dengan baik (Organ, Padsakoff, \& MacKenzie, 2006). Rioux dan Penner (2001) menambahkan OCB sebagai perilaku proaktif yaitu melakukan pekerjaan di luar deskripsi kerja.

Hasil penelitian Crospazano, Byrne, \& Rupp (2003) membuktikan bahwa bila OCB dapat terjadi pada satu organisasi, maka kelelahan kerja (exhaustion) karyawan, intensitas pindah kerja, dan rendahnya kualitas kerja akan dapat ditekan. Pendapat tersebut didukung oleh Hui, Lawa, dan Lam (2000) yang mengatakan bahwa dengan adanya perilaku OCB maka karyawan akan dapat saling membantu atau saling mendukung dalam bekerja yang lebih baik. Keberadaan karyawan dengan perilaku OCB pada organisasi akan mengantarkan perusahaan pada suatu kondisi yang menguntungkan, karena karyawan akan bekerja lebih efektif dan akan ikut bekerja maksimal mempertahankan organisasi jika organisasi dalam kondisi yang kurang baik. OCB merupakan perilaku yang menjadi tuntutan organisasi saat ini. Penelitian telah menunjukkan bahwa dorongan OCB memiliki dampak positif yang kuat pada hasil kerja individual yang bervariasi (Podsakoff, MacKenzie, Paine, \& Bachrach, 2000).

Alasan lain mengapa OCB berperan penting bagi upaya meningkatkan kinerja organisasi adalah mengurangi kebutuhan akan sumber daya-sumber daya yang langka atau mahal untuk fungsi-fungsi perawatan atau perbaikan dalam organisasi (Organ,1988), memberi keleluasaan bagi karyawan untuk lebih produktif (Borman \& Motowidlo, 1993), meningkatkan produktifitas hubungan kerja atau manajerial (Organ, 1988), serta meningkatkan kemampuan organisasi untuk menarik minat dan mempertahankan karyawan terbaiknya untuk bekerja di perusahaan dengan menciptakan suasana kerja yang menyenangkan (Organ,1988). Melihat pentingnya OCB tersebut maka penelitian tentang reliabilitas dan validitas konstruk skala OCB penting dilakukan mengingat perkembangan pemahaman tentang konstruk OCB yang selalu berkembang sebagai sebuah konstruk yang bersifat multidimensi. Penelitian ini dilakukan karena reliabilitas dan validitas konstruk skala OCB yang dipergunakan dalam penelitian ini belum teruji, serta hasil penelitian merupakan bukti yang mendukung atau sebaliknya tidak mendukung multidimensionalitas OCB.

Terdapat lima aspek atau dimensional yang merefleksikan OCB menurut Organ, dkk. 2006) yaitu conscientiousness, altruism, civic virtue, sportmanship, dan courtesy. Conscientiousness, berarti perilaku yang memenuhi atau melebihi syarat minimal peran yang dikehendaki oleh organisasi. OCB juga meliputi ketaatan dan kepatuhan akan peraturan yang berlaku misalnya karyawan mempunyai perilaku datang ke kantor lebih 
awal, tidak membuang waktu dengan mengobrol di telepon atau kantor, tinggi dalam hal kehadirannya, dan melakukan sesuatu melebihi kebutuhan dan harapan normal.

Menurut Organ, dkk. 2006 Altruism merupakan perilaku menolong orang lain dalam konteks masalah kerja dalam organisasi, misalnya menggantikan rekan kerja yang tidak masuk kerja atau istirahat, membantu orang lain yang pekerjaannya overload, membantu proses orientasi karyawan baru meskipun tidak diminta, membantu mengerjakan tugas orang lain pada saat tidak masuk, dan meluangkan waktu untuk orang lain untuk menyelesaikan permasalahan yang dihadapi berhubungan dengan pekerjaan. Civic virtue, yaitu karyawan memberikan kontribusi pada isu-isu politik yang ada dalam organisasi dengan cara yang bertanggung jawab seperti terlibat dan bekerjasama dengan tim serta secara aktif memberikan saran dan kritik yang membangun demi kelangsungan hidup organisasi, memberikan perhatian terhadap pertemuan-pertemuan penting, membaca setiap pengumuman yang serta bertanggung jawab mengumpulkan informasi yang memberikan pengetahuan, isu atau kejadian yang memiliki implikasi bagi organisasi dan menggunakan ketrampilan berpikir kritis untuk mengindentifikasi masalah, kemudian menganalisis dengan hati-hati, serta beropini.

Sportmanship, yaitu lebih menekankan pada aspek-aspek positif organisasi daripada aspek-aspek negatifnya, kemauan karyawan untuk mentoleransi keadaan yang kurang ideal tanpa protes tidak mengeluh, tidak membesar-besarkan masalah kecil/sepele, bersikap tidak meremehkan keadaan atau berbuat masalah, dan tidak membesar-besarkan masalah dalam organisasi. Courtesy, yaitu berbuat baik dan hormat kepada orang lain, termasuk perilaku seperti membantu seseorang untuk mencegah terjadinya suatu permasalahan, atau membuat langkah-langkah untuk meredakan/mengurangi berkembangnya suatu masalah, misalnya pemberian saran konstruktif serta segala informasi sebagai bahan pemecahan permasalahan agar orang lain dapat menggunakannya (Organ, dkk 2006).

Confirmatory Factor Analysis (CFA) merupakan salah satu dari pendekatan utama didalam analisis faktor. CFA dapat digunakan untuk menguji dimensionalitas suatu konstruk (OCB). Pengujian ini digunakan untuk melakukan pengukuran model (model measurement) sehingga dapat menggambarkan aspek-aspek dan indikatorindikator dalam merefleksikan variabel laten yaitu OCB dengan melihat factor loading dari tiap aspek yang membentuk suatu kontruk. Confirmatory Factor Analysis (CFA) juga digunakan untuk menguji validitas konstrak dan reliabilitas konstrak dari indikatorindikator (item-item) pembentuk konstruk laten (Latan, 2012).

Pada penelitian ini CFA yang digunakan adalah Second order confirmatory factor analysis ( $2^{\text {nd }}$ Order CFA) yaitu model pengukuran yang terdiri dari dua tingkat. Tingkat pertama analisis dilakukan dari konstruk laten aspek ke indikator-indikatornya dan kedua analisis dilakukan dari konstruk laten ke konstruk aspeknya (Latan, 2012). Dengan demikian dapat diketahui OCB pada karyawan, validitas konstruk OCB dengan melihat bobot muatan faktor dan nilai $\mathrm{t}$ hitung, menghitung besarnya reliabilitas konstruk OCB menggunakan standar loading faktor masing-masing item dan error masing-masing item, kontribusi aspek-aspek dan indikator-indikator OCB dalam merefleksikan/mengukur variabel OCB dan mengkonfirmasikan model yang dihipotesiskan yaitu kecocokan model dan data. 
Penelitian ini bertujuan pertama untuk menguji validitas konstruk dan reliabilitas konstruk skala OCB, kedua untuk mengetahui kontribusi aspek-aspek dan indikatorindikator OCB dalam merefleksikan/mengukur variabel OCB baik yang paling dominan atau sebaliknya, dan ketiga menguji model teoritik variabel OCB apakah sesuai (fit) dengan data empirik.

\section{Metode Penelitian}

Partisipan dalam penelitian ini adalah karyawan di organisasi X dengan jumlah 202 orang yang berstatus sebagai karyawan tetap dan sudah bekerja minimal 1 tahun. Pengambilan sampel dengan teknik non-probability sampling yang dilakukan dengan convenience sampling. Instrumen yang digunakan untuk mengukur OCB dalam penelitian ini adalah skala OCB yang dikonstruksi sendiri oleh penulis berdasarkan aspek-aspek OCB dari Organ, dkk. (2006) yaitu conscientiousness, altruism, civic virtue, sportmanship, dan courtesy. Skala pengukuran yang dipergunakan adalah skala likert dengan empat katagori yaitu jawaban dari pertanyaan sangat tidak sesuai diberi skor 1, tidak sesuai diberi skor 2, sesuai diberi skor 3 dan sangat sesuai diberi skor 4 . Skala ini mempunyai dua bentuk pernyataan yaitu favorable dan unfavorable. Angka 1/STS merupakan nilai terendah yang mencerminkan bobot terendah yang diberikan responden terhadap suatu item/pernyataan dan angka 4/SS merupakan nilai tertinggi yang mencerminkan bobot tertinggi yang diberikan responden terhadap suatu item/pernyataan. Indikator-indikator yang merefleksikan masing-masing aspek itu adalah sebagai berikut:

Tabel 1.

Aspek dan Indikator OCB

\begin{tabular}{|c|c|c|}
\hline No & Aspek & Indikator \\
\hline 1 & Conscientiousness & $\begin{array}{l}\text { a. Ketaatan dan kepatuhan pada peraturan organisasi } \\
\text { b. Melakukan pekerjaan diluar pekerjaan formal yang melebihi } \\
\text { syarat minimal peran yang dikehendaki organisasi }\end{array}$ \\
\hline 2 & Altruism & $\begin{array}{l}\text { a. Membantu tugas rekan kerja dalam bekerja } \\
\text { b. Mengerjakan tugas rekan kerja yang tidak hadir }\end{array}$ \\
\hline 3 & Civic virtue & $\begin{array}{l}\text { a. Terlibat dalam kegiatan organisasi } \\
\text { b. Peduli terhadap kelangsungan hidup organisasi }\end{array}$ \\
\hline 4 & Sportmanship & $\begin{array}{l}\text { a. Adanya toleransi terhadap kekurangan organisasi } \\
\text { b. Menjaga nama baik organisasi }\end{array}$ \\
\hline 5 & Courtesy & $\begin{array}{l}\text { a. Mencegah timbulnya masalah yang terkait pekerjaan dengan } \\
\text { rekan kerja } \\
\text { b. Membantu memberikan saran kepada rekan kerja yang } \\
\text { kesulitan terhadap masalah/tugas }\end{array}$ \\
\hline
\end{tabular}


Blue Print Skala OCB terdapat pada tabel 2 di bawah ini.

Tabel 2.

\section{Blue Print Skala OCB}

\begin{tabular}{|c|c|c|c|c|c|}
\hline \multirow[t]{2}{*}{ No } & \multirow[t]{2}{*}{ Aspek } & \multirow[t]{2}{*}{ Indikator } & \multicolumn{2}{|c|}{ No. Item } & \multirow[t]{2}{*}{$\sum$} \\
\hline & & & Favo & Unfavo & \\
\hline \multirow[t]{2}{*}{1} & Conscientiousness & $\begin{array}{l}\text { a. Ketaatan dan kepatuhan pada peraturan } \\
\text { organisasi }\end{array}$ & 1 & 6 & 2 \\
\hline & & $\begin{array}{l}\text { b. Melakukan pekerjaan diluar pekerjaan formal } \\
\text { yang melebihi syarat minimal peran yang } \\
\text { dikehendaki organisasi }\end{array}$ & 11 & 16 & 2 \\
\hline \multirow[t]{2}{*}{2} & Altruism & $\begin{array}{l}\text { a. Membantu tugas rekan kerja dalam bekerja } \\
\text { b. Mengeriakan tugas rekan keria vang tidak hadir }\end{array}$ & 2 & 7 & 2 \\
\hline & & & 12 & 17 & 2 \\
\hline \multirow[t]{2}{*}{3} & Civic virtue & a. Terlibat dalam kegiatan organisasi & 3 & 8 & 2 \\
\hline & & b. Peduli terhadap kelangsungan hidup organisasi & 13 & 18 & 2 \\
\hline \multirow[t]{2}{*}{4} & Sportmanship & $\begin{array}{l}\text { a. Adanya toleransi terhadap kekurangan organisasi } \\
\text { b. Menjaga nama baik organisasi }\end{array}$ & 4 & 9 & 2 \\
\hline & & & 14 & 19 & 2 \\
\hline \multirow[t]{3}{*}{5} & Courtesy & $\begin{array}{l}\text { a. Mencegah timbulnya masalah yang terkait } \\
\text { pekerjaan dengan rekan kerja }\end{array}$ & 5 & 10 & 2 \\
\hline & & $\begin{array}{l}\text { b. Membantu memberikan saran kepada rekan kerja } \\
\text { yang kesulitan terhadap masalah/tugas }\end{array}$ & 15 & 20 & 2 \\
\hline & Total Item & & & & 20 \\
\hline
\end{tabular}

Validitas dan reliabilitas konstruk dari indikator-indikator (item-item) pembentuk konstruk laten dengan melakukan Confirmatory Factor Analysis (CFA) (Latan, 2012). Pengujian validitas dan realibilitas instrumen dilakukan agar dalam melakukan penelitian dengan menggunakan analisis faktor konfirmatori didapatkan data yang valid dan reliabel. Dengan kata lain pengujian ini digunakan untuk melakukan pengukuran model (model measurement) untuk menggambarkan sebaik apa aspekaspek dan indikator-indikator dapat digunakan sebagai pengukuran OCB.

Second order confirmatory factor analysis (2nd Order CFA) adalah model pengukuran yang terdiri dari dua tingkat. Tingkat pertama analisis dilakukan dari konstruk laten aspek ke indikator-indikatornya dan kedua analisis dilakukan dari konstruk laten ke konstruk aspeknya (Latan, 2012). Menurut Hair, Black, Babin, \& Anderson (2010), melalui CFA tidak hanya dapat dilakukan pengujian validitas konstrak (Construct Validity), tetapi juga reliabilitas konstruk (Construct Reliability).

Pengujian 2nd Order CFA ini dilakukan dengan melihat nilai muatan faktor (>0.5) dan nilai t hitung $(>1,96)$. Bobot muatan faktor sebesar 0,50 atau lebih dianggap memiliki validitas yang cukup kuat untuk menjelaskan konstruk laten (Hair, dkk., 2010 \& Ghozali, 2012). Sharma (1996) menjelaskan bahwa muatan faktor paling lemah yang bisa diterima adalah 0,40 .

Hair, dkk., (2010) menyatakan bahwa konstruk mempunyai reliabilitas yang baik adalah jika nilai Construct Reliability (CR) $\geq 0,70$ dan nilai variance extracted $\geq$ 0,50. Hair, dkk., (2010) menambahkan interpretasi terhadap ukuran konstruk reliabilitas sudah dapat dikatakan baik jika nilainya lebih dari 0,40 . Besarnya reliabilitas (Construct Reliability) maka digunakan rumus dibawah ini (Hair, dkk., 2010; Wijayanto, 2008) 


$$
\begin{aligned}
& \mathrm{CR}=\frac{\left(\sum \mathrm{SLF}\right)^{2}}{\left(\sum \mathrm{SLF}\right)^{2}}+\left(\sum \mathrm{e}\right) \\
& \mathrm{VE}=\frac{\sum \mathrm{SLF}^{2}}{\sum \mathrm{SLF}^{2}+\left(\sum \mathrm{e}\right)}
\end{aligned}
$$

Keterangan:

CR (Construct Reliability) : Konsistensi suatu pengukuran

VE (Variance Ektracted) : Jumlah varian keseluruhan dalam variabel manifes yang dapat dijelaskan oleh variabel laten

¿SLF : Jumlah standar loading faktor masing-masing item $\sum \mathrm{e} \quad$ : Jumlah error masing-masing item

(Hair, dkk., 2010; Wijayanto, 2008)

Metode analisis data dilakukan dengan Structural Equation Model (SEM) menggunakan Linear Structural Model (LISREL) versi 8.71 dari Joreskog dan Sorbom (2008) melalui 2nd Order CFA.

\section{Hasil dan Pembahasan}

Analisis data dilakukan dengan menggunakan program LISREL dengan kriteria nilai muatan faktor $(>0.5)$ dan nilai t hitung $(>1,96)$ yang hasilnya dapat dilihat pada gambar berikut:

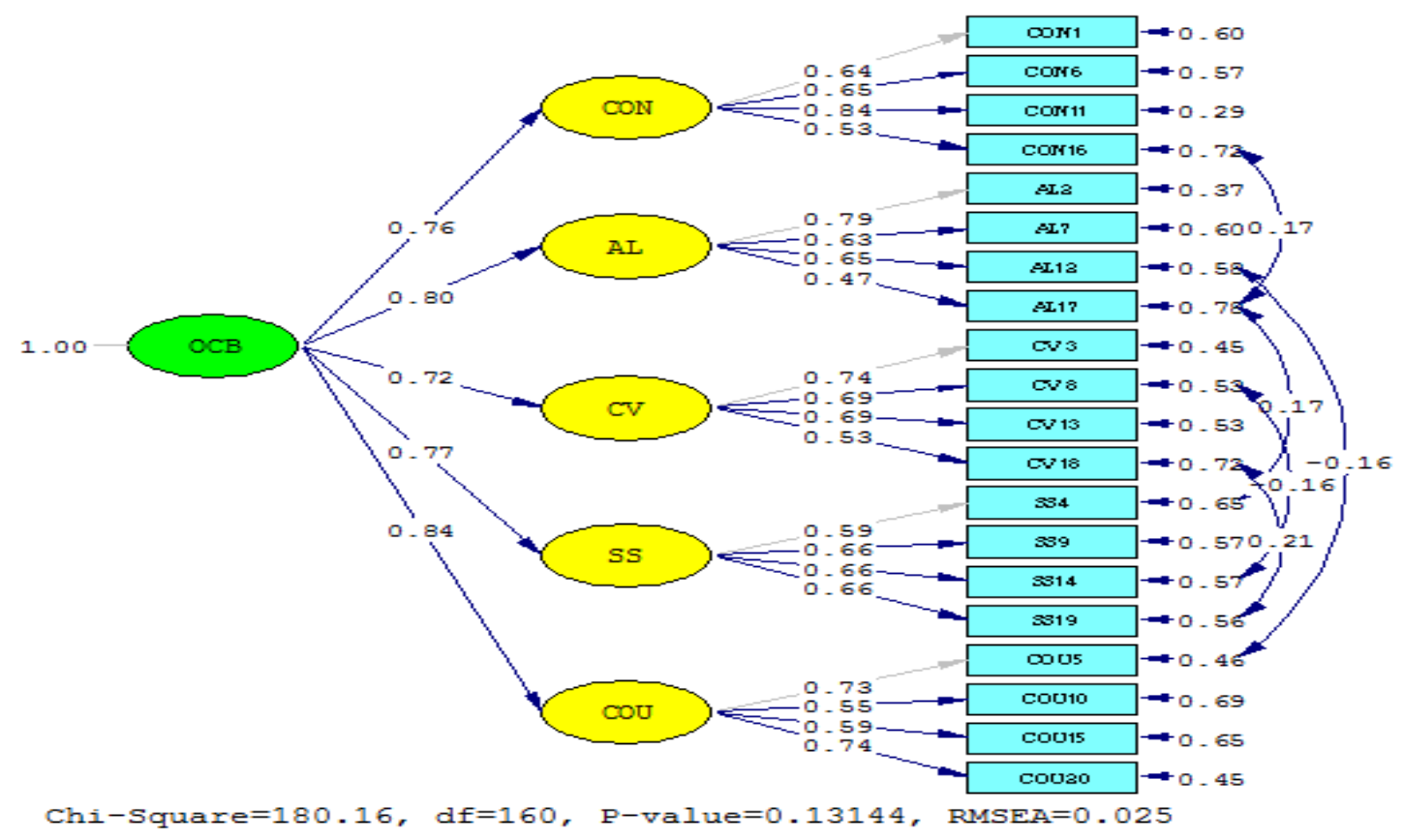

Gambar 1. Nilai muatan faktor $2^{\text {nd }} \mathrm{Order} C F A$ OCB 


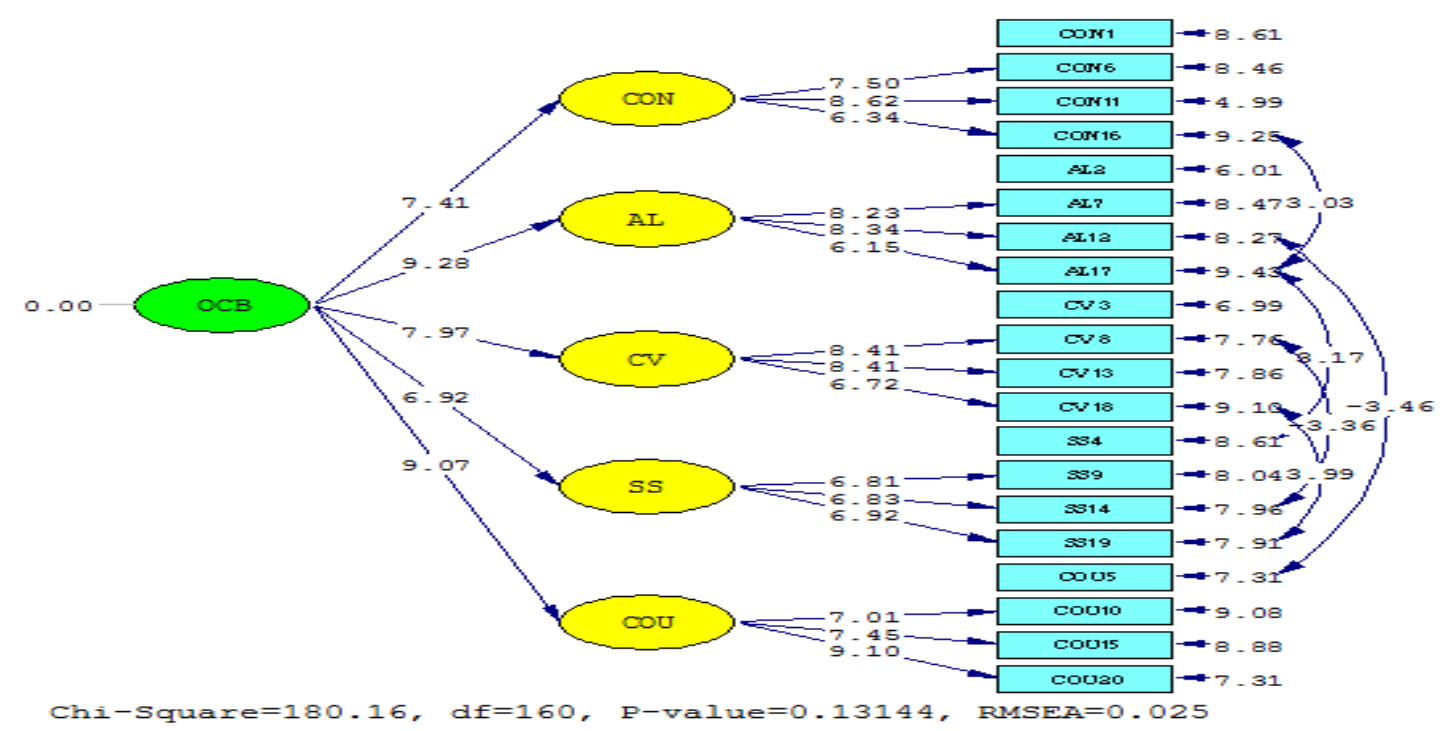

Gambar 2. Nilai t $2^{\text {nd }}$ Order CFA OCB

Tingkat pertama analisis dilakukan dari konstruk laten aspek ke indikatorindikatornya. Berdasarkan hasil analisis di atas menunjukkan bahwa nilai loading faktor semuanya $>0,5$ dan semua nilai t hitung yang diperlukan untuk menguji signifikansi nilai loading faktor lebih besar dari 1,96. Hal ini berarti dari 20 item yang mengukur OCB tersebut, seluruhnya merupakan item yang valid dan signifikan terhadap OCB. Rangkuman hasil analisis tersebut dapat dilihat pada tabel berikut ini:

Tabel 2.

Hasil Analisis 2nd Order CFA Construct Validity OCB (Aspek-Indikator)

\begin{tabular}{rcccc}
\hline No. & Item & Muatan Faktor & T-Value & Keterangan \\
\hline 1 & CON1 & 0,64 & & \\
2 & CON6 & 0,65 & 7,50 & $\mathrm{Sig}$ \\
3 & CON11 & 0,84 & 8,62 & $\mathrm{Sig}$ \\
4 & CON16 & 0,53 & 6,34 & $\mathrm{Sig}$ \\
5 & AL2 & 0,79 & & $\mathrm{Sig}$ \\
6 & AL7 & 0,63 & 8,23 & $\mathrm{Sig}$ \\
7 & AL12 & 0,65 & 8,34 & $\mathrm{Sig}$ \\
8 & AL17 & 0,47 & 6,15 & $\mathrm{Sig}$ \\
9 & CV3 & 0,74 & & $\mathrm{Sig}$ \\
10 & CV8 & 0,69 & 8,41 & $\mathrm{Sig}$ \\
11 & CV13 & 0,69 & 8,41 & $\mathrm{Sig}$ \\
12 & CV18 & 0,53 & 6,72 & $\mathrm{Sig}$ \\
13 & SS4 & 0,59 & & $\mathrm{Sig}$ \\
14 & SS9 & 0,66 & 6,81 & $\mathrm{Sig}$ \\
15 & SS14 & 0,66 & 6,83 & $\mathrm{Sig}$ \\
16 & SS19 & 0,66 & 6,92 & $\mathrm{Sig}$ \\
17 & COU5 & 0,73 & & 7,01 \\
18 & COU10 & 0,55 & 7,45 & 9,10 \\
19 & COU15 & 0,59 & & \\
20 & COU20 & 0,74 & & \\
\hline
\end{tabular}

Tingkat kedua analisis dilakukan dari konstruk laten ke konstruk aspeknya. Berdasarkan hasil pengujian di atas menunjukkan bahwa nilai loading faktor semuanya $>0,5$ dan semua nilai t hitung yang diperlukan untuk menguji signifikansi nilai loading 
faktor lebih besar dari 1,96. Rangkuman hasil analisis tersebut dapat dilihat pada tabel berikut ini.

Tabel 3.

Hasil Analisis 2nd Order CFA Construct Validity OCB (Laten-Aspek)

\begin{tabular}{ccccc}
\hline No. & Aspek & Muatan Faktor & T-Value & Keterangan \\
\hline 1 & Conscientiousness & 0,76 & 7,41 & Sig \\
2 & Altruism & 0,80 & 9,28 & Sig \\
3 & Civic Virtue & 0,72 & 7,97 & Sig \\
4 & Sportmanship & 0,77 & 6,92 & Sig \\
5 & Courtesy & 0,84 & 9,07 & Sig \\
\hline
\end{tabular}

Hasil tersebut menunjukkan bahwa kelima aspek OCB yang terdiri dari conscientiousness, altruism, civic virtue, sportmanship, dan courtesy dikatakan valid dan signifikan untuk mengukur variabel laten OCB. Hasil validitas tersebut didukung juga dengan nilai Chi Square (r) yang menghasilkan nilai 180,16 dengan p-value 0,131 $(\mathrm{p}>0,05)$.

Berdasarkan rumus perhitungan konstruk reliabilitas diperoleh hasil $\mathrm{CR}=0,94$ dan $\mathrm{VE}=0,43$ yang berarti bahwa skala OCB memiliki reliabilitas yang baik. Hair, dkk., (2010) menyatakan bahwa konstruk mempunyai reliabilitas yang baik adalah jika nilai Construct Reliability $(\mathrm{CR}) \geq 0,07$ dan nilai variance extracted $(\mathrm{VE}) \geq 0,40$.

Tabel 4.

Hasil Analisis 2nd Order CFA Cunstruct Reliability $O C B$

\begin{tabular}{|c|c|c|c|c|c|}
\hline No. & Item & Muatan Faktor & Eror & CR & VE \\
\hline 1 & CON1 & 0,64 & 0,60 & & \\
\hline 2 & CON6 & 0,65 & 0,57 & & \\
\hline 3 & CON11 & 0,84 & 0,29 & & \\
\hline 4 & CON16 & 0,53 & 0,72 & & \\
\hline 5 & AL2 & 0.79 & 0,37 & & \\
\hline 6 & AL7 & 0,63 & 0,60 & & \\
\hline 7 & AL12 & 0,65 & 0,58 & & \\
\hline 8 & AL17 & 0,47 & 0,78 & & \\
\hline 9 & $\mathrm{CV} 3$ & 0,74 & 0,45 & & \\
\hline 10 & CV8 & 0,69 & 0,53 & 0,94 & 0,43 \\
\hline 11 & CV13 & 0,69 & 0,53 & & \\
\hline 12 & CV18 & 0,53 & 0,72 & & \\
\hline 13 & SS4 & 0,59 & 0,65 & & \\
\hline 14 & SS9 & 0,66 & 0,57 & & \\
\hline 15 & SS14 & 0,66 & 0,57 & & \\
\hline 16 & SS19 & 0,66 & 0,56 & & \\
\hline 17 & COU5 & 0,73 & 0,46 & & \\
\hline 18 & COU10 & 0,55 & 0,69 & & \\
\hline 19 & COU15 & 0,59 & 0,65 & & \\
\hline 20 & COU20 & 0,74 & 0,45 & & \\
\hline
\end{tabular}

Selanjutnya untuk kesesuaian modelnya (model fit), secara umum sudah bagus. Adapun kriteria model fit-nya adalah seperti pada tabel berikut. 
Tabel 5.

Kriteria Model Fit

\begin{tabular}{ccccc}
\hline No & Indeks Fit & Nilai & Nilai Standar & Keterangan \\
\hline 1 & Chi Square $\mathrm{p}$ & $180,16(\mathrm{df}=160, \mathrm{p}=0,13$ & $>0,05$ & Fit \\
& & ) & & Fit \\
3 & RMSEA & 0,025 & $>0,08$ & Fit \\
4 & NFI & 0,95 & $>0,90$ & Fit \\
5 & NNFI & 0,99 & $>0,90$ & Fit \\
6 & CFI & 0,99 & $>0,90$ & Fit \\
7 & IFI & 0,99 & $>0,90$ & Fit \\
8 & GFI & 0,92 & $>0,90$ & Tidak Fit \\
\hline
\end{tabular}

Berdasarkan hasil analisis diketahui sebanyak 7 dari 8 indeks fit menyatakan bahwa model fit. Hasil ini menunjukkan bahwa model teoritik variabel OCB sesuai (fit) dengan data empirik.

Berdasarkan hasil analisis validitas konstrak dan reliabilitas konstrak maka semua aspek-aspek dan item-item yang membentuk OCB karyawan dinyatakan valid dan reliabel sehingga semua aspek dan indikator tersebut mampu merefleksikan dan membentuk OCB karyawan. Aspek paling dominan yang merefleksikan OCB adalah aspek altruism dimana indikator utamanya adalah membantu tugas rekan kerja dalam bekerja dan mengerjakan tugas rekan kerja yang tidak hadir. Perilaku spesifiknya adalah membantu rekan kerja yang tugasnya overload, menggantikan rekan kerja yang tidak masuk kerja, membantu proses orientasi rekan kerja baru meskipun tidak diminta, dan meluangkan waktu membantu rekan kerja.

Aspek paling rendah yang merefleksikan OCB karyawan adalah sportmanship dengan indikator utama adalah adanya toleransi terhadap kekurangan organisasi dan menjaga nama baik organisasi. Perilaku spesifiknya adalah tidak mudah mengeluh terhadap fasilitas organisasi yang minim seperti ruang kerja, tempat parkir, fasilitas bekerja dan lain-lain, tidak mudah komplain atas kekurangan-kekurangan organisasi, tidak membicarakan keburukan organisasi dibandingkan organisasi lainnya, tidak membesar-besarkan masalah kecil, dan menjaga nama baik organisasi.

\section{Simpulan dan Saran}

Pengujian dengan Second order confirmatory factor analysis (2nd Order CFA) pada skala OCB menunjukkan bahwa skala OCB valid dan reliabel sehingga skala OCB versi Indonesia bisa dimanfaatkan secara maksimal sebagai alat untuk mengukur mengukur OCB pada karyawan. OCB mampu direfleksikan dalam lima aspek pembentuk OCB yaitu conscientiousness, altruism, civic virtue, sportmanship, dan courtesy. Aspek paling dominan yang merefleksikan OCB adalah aspek altruism dan aspek paling lemah adalah sportmanship. Bukti tentang multidimensionalitas OCB dapat terbukti dikarenakan seluruh aspek dalam alat ukur ini memenuhi kriteria-kriteria sebagai item yang baik. Bagi penelitian selanjutnya, peneliti menyarankan untuk memahami sepenuhnya tentang konsep OCB dan model konseptual yang digunakan dan peneliti juga mampu untuk memilih model yang tepat agar dapat sesuai dengan kondisi internal subjek atau organisasi, selain itu dalam menyusun aspek aspek OCB juga perlu memperhatikan aspek budaya dan adat istiadat setempat. 


\section{Daftar Pustaka}

Borman, W.C., \& Motowidlo, S. J. (1993). Expanding the criterion domain to include elements of extra-role performance. Dalam Schmitt, N \& Borman, W.C. (ed), Personnel Selection in Organizations. San Francisco: Jossey-Bass.

Crospazano, R., Byrne, Z.S., \& Rupp, A.E. (2003). The relationship of emotional

exhaustion to work attitudes, job performance, and organizational citizenship behavior. Journal of Apllied Psychology, 88(1),160-169.

Ghozali I., \& Fuad. (2012). Structural equation modeling, teori,konsep dan aplikasi dengan program LISREL 8,8. Semarang: Universitas Diponegoro.

Hair, J.F., Black, W.J., Babin, B.J., \& Anderson, R.E. (2010). Multivariate data analysis. Englewood Cliff, NJ: Prentice Hall.

Hasibuan, M.S.P. (2012). Manajemen sumber daya manusia. Jakarta: Bumi Aksara.

Hui, C., Lawa, K.K.S., \& Lam, S.S.K. (2000). Instrumental values of organizational citizenship behavior for promotin: A field quasi-experiment. Journal of Apllied Psychology, 85(5), 822-828.

Joreskog, K. \& Sorbom, D. (2008). Lisrel 7: A guide to the program and applications $\left(2^{\text {nd }}\right.$ edition). Chicago:, Inc.

Latan, H. (2012). Structural equation modeling konsep dan aplikasi menggunakan LISREL 8,80. Bandung: Alfabeta

Organ, D.W. (1988). Organizational citizenship behavior: The good soldier syndrome. Lexington. MA: Lexington Books.

Organ, D.W., Padsakoff, P.M., \& MacKenzie, S.B. (2006). Organizational citizenship behaviour: Its nature, antecendents, and consequences. USA: Sage Publication.

Podsakoff, P.M., MacKenzie, S.B., Paine, J.B., \& Bachrach, D.G. (2000). Organizational citizenship behaviors: A critical review of the theoretical and empirical literature and suggestions for future research. Journal of Management, 26(3), 513-563.

Rebbeca, Y. H., \& Niehoff, B. P. (2002). Relationships between organizational citizenship behaviors, efficiency, and customer service perceptions in Taiwanese Banks. Journal Midwest Academy. Retrieved from http://www.midwest academy.org/Proceedings/2002/papers/Yen.doc.

Rioux S. M., \& Penner, L.A. (2001). The cause of organizatonal citizenship behavior: A motivational analysis. Journal Apllied Psychology, 86(6), 1306-1314.

Sharma, S. (1996). Applied multivariate techniques. John Wiley \& Sons. Inc.

Wijayanto, S.H. (2008). Structural equation modeling dengan LISREL 8.8. Yogyakarta: Graha Ilmu 